\title{
"MULHERES PERANTE A LEI NA CATALUNHA MODERNA": REFLEXÕES SOBRE A NOVA HISTÓRIA PARA A COMPREENSÃO DE FENÔMENOS SOCIOJURÍDICOS
}

\author{
"WOMEN BEFORE THE LAW IN MODERN CATALONIA": REFLECTIONS ON \\ THE NEW HISTORY TO UNDERSTANDING SOCIO-JURIDICAL PHENOMENA
}

${ }^{1}$ Maria Tereza Fonseca Dias

\section{RESUMO}

Este trabalho tem por escopo refletir sobre as metodologias da "Nova História", a partir do estudo da obra Las mujeres ante la ley en la Cataluña moderna, de Isabel Pérez Molina, que retrata a condição das mulheres na Idade Moderna. O objetivo do trabalho foi avaliar quais os elementos metodológicos desta "Nova História" contribuem para a compreensão dos fenômenos sociojurídicos do passado. A metodologia utilizada foi a pesquisa bibliográfica interdisciplinar. Considerando os aspectos e temáticas que a "Nova História" pode abordar, concluiu-se que ela contribui para a construção e compreensão dos fenômenos sociojurídicos do passado, notadamente nas temáticas de gênero.

Palavras-chave: "nova história", História das mulheres, Metodologia da história, Idade moderna

\begin{abstract}
This work reflects on the methodologies of "New History" (Nouvelle Histoire), from the book "Women before the law in Modern Catalonia", written by Isabel Pérez Molina, who portrays the condition of women in the Modern Age. The objective was to evaluate which of the methodological elements of this "New History" contribute to understanding the sociojuridical phenomena of the past. The methodological approach used included interdisciplinary literature. Considering the aspects and subject-matter that the "New History" can address, the analysis concluded that it contributes to the construction and understanding of the socio-juridical phenomena of the past, notably in gender affairs.
\end{abstract}

Keywords: "new history", Women's history, Methodology of history, Modern age

\footnotetext{
${ }^{1}$ Doutora em Direito pela Universidade Federal de Minas Gerais - UFMG, Belo Horizonte - MG (Brasil). Professora da Universidade Federal de Minas Gerais - UFMG, Belo Horizonte - MG (Brasil).

E-mail: mariaterezafdias@yahoo.com.br
} 


\section{INTRODUÇÃO}

O presente trabalho tem por escopo promover reflexões sobre as metodologias da "Nova História" (Nouvelle Histoire) para a compreensão dos fenômenos jurídicos do passado. ${ }^{1}$

Segundo Peter Burke, "Os historiadores tradicionais pensam na história como essencialmente uma narrativa dos acontecimentos, enquanto a nova história está mais preocupada com a análise das estruturas." (BURKE, 1990, p. 12)

Estas reflexões serão promovidas a partir da pesquisa histórica Las mujeres ante la ley en la Cataluña moderna, de Isabel Pérez Molina, da Universidade de Granada, obra que retrata as mulheres na Idade Moderna, passando, em seguida, para a descrição da condição social das mulheres na Europa, na Espanha e na Catalunha. A obra foi estruturada a partir da discussão dos seguintes temas e capítulos: cultura, trabalho, as bruxas, reforma e contrarreforma, as mudanças do Século XVIII e a família. A escolha deste trabalho deveuse ao fato de que o mesmo tratou de descrever a metodologia utilizada para a compreensão do fenômeno histórico- jurídico - o que permitiu compreender o papel da Nova história neste processo.

A temática abordada por Perez Molina é a história das mulheres e o direito e, segundo a autora, foi escolhida pelo fato de que "[...] no decurso dos últimos anos a história das mulheres foi uma das áreas de investigação mais ativas e frutíferas no quadro da historiografia" (PEREZ MOLINA, 2008, p. 11).

Este tema, segundo a autora, funciona como critério metodológico de pesquisa, haja vista que os gêneros (homem/mulher) passam a ser utilizados como categoria histórica de análise, ou seja, através dessa abordagem os textos históricos passam a ser lidos através de outro prisma. Assim, (re) inserir a mulher na história da humanidade cria nova categoria de análise conceitual e novo modelo interpretativo dos dados, de forma a questionar o que antes se concebia como uma história em neutro/masculino ${ }^{2}$.

\footnotetext{
1 Neste trabalho utilizou-se a expressão "Nouvelle Histoire" em seu sentido ampliado, que inclui a Escola dos Annales e a Nova História em sentido estrito, desenvolvida a partir da década de 1970, conforme a concepção de José Carlos Reis (1994).

2 Nesse sentido Pérez Molina (2008) afirma que os homens descreveram e valoraram sua experiência, denominando-a "História Universal".
} 
A autora acredita que somente através dessa perspectiva é que se constrói uma verdadeira "História Total", tal como propugnada pela Escola dos Annales ${ }^{3}$, notadamente por Braudel ${ }^{4}$ e Fèbvre. Pérez Molina, dessa forma, não compreende a "História Total" como conjunto de dados empíricos e de pensamento ("mentalidades") descritos num determinado tempo e espaço, mas uma história de homens e de mulheres.

$\mathrm{Na}$ análise da história das mulheres feita por Pérez Molina, percebeu-se a influência de elementos da "Nova História", tais como o tratamento de novas temáticas mais relacionados ao quotidiano e à marginalidade.

Apesar de suas peculiaridades, os novos métodos históricos possuem similitudes que os contrapõem veementemente aos métodos tradicionais. Entre as características dos novos métodos históricos destaca-se, a recusa de uma história superficial e simplista, preocupada tão somente com a busca das origens, daí por que os historiadores estão sempre à procura de um conhecimento profundo e total.

A preocupação com a metodologia da história na compreensão dos fenômenos sociojurídicos revela-se no fato de que a produção acadêmica do conhecimento jurídico em teses e dissertações, em que pese quase sempre contar com um capítulo dedicado à história - história do direito, história de algum instituto jurídico ou a história de um personagem de relevo no mundo jurídico - raras vezes revela o cuidado metodológico necessário para a tal fim.

António Manuel Hespanha, ao tratar da necessidade de fazer história do direito a partir de questionamentos, de fundamentos e de métodos afirmou que "[...] a tarefa historiográfica não pode decorrer sem a adesão a um modelo explicativo prévio que permita seleccionar as questões relevantes e relacioná-las entre si, adoptar as estratégias de pesquisa adequadas, estabelecer ligações entre os factos apurados pela investigação empírica." (HESPANHA, 1978, p. 16).

\footnotetext{
3 A Escola dos Annales é uma das mais notáveis escolas históricas, cuja atividade começou no início do Século XX. No âmbito desta verdadeira escola de pensamento, "A História inclui qualquer traço ou vestígio das coisas que o homem fez ou pensou, desde o seu surgimento sobre a terra [...] Por método, 'A Nova História deverá utilizar-se de todas as descobertas sobre a humanidade, que estão sendo feitas por antropólogos, economistas, psicólogos e sociólogos"” (ROBINSON apud BURKE, 1997, p. 20)

4 Afirma Peter Burke que “[...] a obra de Braudel é importante por sua síntese entre o que pode ser denominado a 'pequena história' do diaa-dia, facilmente transformável em mera descrição, anedotário ou antiquarismo, e a história das grandes tendências socioeconômicas da época". (BURKE, 1997, p. 60)
} 
Segundo Miracy Gustin, quando se preocupam em descrever a metodologia utilizada, essas histórias do direito foram e ainda são escritas através de uma "metodologia tradicional" do conhecimento histórico. Para a autora,

[...] é preciso entender que 'História do Direito' é história, porquanto o historiador do Direito utiliza-se de metodologias próprias à ciência histórica e relaciona-se com os novos problemas e novos objetos das ciências auxiliares da História. (GUSTIN et al, 2007, p. 26)

De toda a fundamentação dada do conhecimento histórico ao longo do tempo - que de resto coincide com aquela dada ao conhecimento científico - parte-se do pressuposto que, para que possa existir a corroboração ou a falsificabilidade ${ }^{5}$ do conhecimento histórico, é mister que se produza o mínimo indispensável para que isso aconteça: a utilização de uma metodologia.

Nesse sentido, Pedro Demo afirma que “A falta de preocupação metodológica leva à mediocridade fatal” (DEMO, 1995, p. 12)

Além da influência marcante do Positivismo, a história do Direito, metodologicamente falando, não tem trabalhado a relação constante que deve existir entre o arcabouço teórico da pesquisa desenvolvida, os dados da realidade e as percepções levantadas sobre o objeto de pesquisa.

Assim, as introduções históricas das teses e dissertações na área jurídica são, em sua grande maioria, capítulos à parte do trabalho e/ou mera compilação de textos doutrinários pouco embasados e documentados.

No que concerne ao material de pesquisa e de fontes, não há, ainda, farta bibliografia de metodologia da história aplicada ao Direito, nem mesmo estudos históricos aprofundados sobre o direito e suas instituições, de forma a compreendê-lo de maneira transdisciplinar $^{6}$ - em que pese os diversos esforços recentes em fazê-lo, como ilustram as obras de Hespanha (1978), em Portugal e de Wolkmer (2010), no Brasil.

Wolkmer, apontando as transformações recentes na história do direito, conclui que

\footnotetext{
5 Segundo o sentido atribuído por Karl Popper (1993) em sua famosa obra "A lógica da pesquisa científica" publicada pela primeira vez em Nova Iorque, no ano de 1968.

${ }^{6}$ Uma disciplina possui natureza transdisciplinar quando se institui além das tradicionais fronteiras disciplinares (MIAILLE, 1989, p. 61)
} 
As profundas mudanças epistemológicas nas ciências humanas, os novos interesses (bioética, biodiversidade, ecologia, desenvolvimento sustentável, realidade virtual), a insurgência global de múltiplos conflitos sociais e as recentes transformações por que vêm passando as formas de vida contemporânea determinam uma renovação metodológica nos estudos históricos das instituições jurídicas e políticas. (WOLKMER, 2010, p. 21)

Colocadas estas questões como pano de fundo, o problema deste trabalho foi identificar, num exercício comparativo, a influência da "Nova História" no trabalho de Pérez Molina, avaliando, que elementos metodológicos desta nova história podem contribuir para a construção e compreensão dos fenômenos sociojurídicos do passado, notadamente na temática das mulheres. Procurou também explorar, como questão secundária, a possibilidade de existir uma história total, de homens e mulheres.

A metodologia utilizada foi a pesquisa bibliográfica interdisciplinar em textos de metodologia da história, história e história do direito, nacionais e estrangeiros, que explorassem a evolução das correntes de pensamento desta metodologia.

\section{2 "HISTÓRIA TRADICIONAL" E "NOVA HISTÓRIA": ALGUMAS CORRENTES METODOLÓGICAS DA HISTÓRIA}

\subsection{Principais aspectos da "História tradicional"}

A metodologia da história tradicional foi diretamente influenciada pelo Positivismo e exerce grande influência na construção da história do direito até os dias atuais. Dentre suas principais características, podemos dizer que a história tradicional:

a) é uma história preocupada em construir o conhecimento através do reflexo fiel dos fatos do passado;

b) procura eliminar todo fator subjetivo do conhecimento histórico;

c) construiu a figura do historiador imparcial;

d) é uma história vista como conjunto de fatos bem documentados. 
O positivismo, principal corrente da "História tradicional", segundo Peter Burke (1997, p. 19) não era um movimento hegemônico, tendo em vista a produção de Michelet, Burckardt, Fustel de Coulanges e Marx, tendo congregado, por esta razão, diversas outras correntes metodológicas da história, das quais podem se destacar além do positivismo, o presentismo $^{7}$ e a história social ou marxismo ${ }^{8}$.

A partir dos trabalhos de Le Goff; Duby; Ariès (1986) e Adam Schaff (1980), apresentam-se os seguintes elementos do positivismo histórico, cujo principal expoente foi Leopold von Ranke, que influenciou historiadores ao menos três séculos posteriores, sendo referência até nossos dias ${ }^{9}$. A característica mais relevante desta corrente de pensamento, é primeiramente, não criar uma interdependência, na relação entre o sujeito/objeto do conhecimento histórico, que são vistos como objetos distintos. Quanto a relação tempo/espaço, além da indefinição de espaço, há uma preocupação pela busca das origens e a teleologia da história é contar o que realmente se passou - como reflexo fiel dos fatos do passado - em oposição à historiografia moralizante anterior a esta corrente.

Hegel, citado por Schaff, considerava o conhecimento histórico “[...] como uma recepção passiva e um reflexo fiel dos fatos” (HEGEL apud SCHAFF,1980, p. 106).

O historiador, por esta razão, deve ser imparcial e promover, do ponto de vista metodológico, a narrativa dos acontecimentos. Trata-se, segundo Leopold von Ranke, de uma "cripto-metafísica", que trata a história "[...] como realidade plenamente reconstituída pelo historiador que a observa. (SCHAFF,1980, p. 104)

\footnotetext{
7 O presentismo, enquanto reação ao Positivismo tem Hegel como seu precursor ao propugnar a inserção do fato subjetivo na história. Benedetto Croce, o "pai cultural" desta corrente, segundo Schaff, afirmou que "[...] a história é o pensamento contemporâneo projetado no passado" (SCHAFF,1980, p.108) e, por esta razão, fundada numa filosofia do espírito, pois: “[...] a esfera espiritual estende-se não apenas às atividades teóricas, mas também às atividades materiais, práticas” (SCHAFF,1980, p.108) e a intuição é o fundamento da existência da história porque cria o objeto de conhecimento.

8 Influenciada pelo marxismo, esta corrente desloca a análise dos acontecimentos históricos do plano individual para o plano social e oletivo fundado na relação cognitiva da linguagem da abstração filosófica para a linguagem do concreto dos estudos históricos. Tem como principais expoentes: Adam Schaff; Kalr Mannheim; E.P.Thompson e Davis e como objeto central de análise a história política.

9 Cf. sobre o autor e sua obra: MATA, Sérgio da. Ranke reloaded: entre história da historiografia e história multiversa. História da historiografia, Ouro Preto, n. 6, mar, 2011, p. 247-251.
} 
A principal fonte de pesquisa no positivismo é documental e, por isto, a ciência histórica é um conjunto suficiente de fatos bem documentados. O conteúdo e temático está relacionado, em geral, à história dos grandes eventos, à narrativa dos acontecimentos políticos e militares; à crônica monástica, memória política e tratados de antiquários.

Como principais críticas a esta corrente tem-se as seguintes assertivas:

- no conhecimento histórico, o sujeito e o objeto constituem uma totalidade orgânica, agindo um sobre o outro e vice-versa;

- a relação cognitiva nunca é passiva, contemplativa, mas ativa por causa do sujeito que conhece;

- o conhecimento e o comprometimento do historiador estão sempre socialmente condicionados; o historiador tem sempre um "espírito de partido".

A partir destas críticas, outras escolas de pensamento da metodologia da história foram se constituindo, entre as quais se destacam a Escola dos Annales, a história da cultura, história das "mentalidades" e a Nova História, esta última considerada a terceira geração da Escola dos Annales, como descrito a seguir. A "Nova História" tem como aspecto central o fato de aglutinar diversas concepções distintas sobre a forma de como melhor tratar da construção da história.

\subsection{Principais aspectos da "Nova História"}

Esta "Nova História" é construída através de uma multiplicidade de fontes, e da necessidade de "ler nas entrelinhas".

Quanto a esta multiplicidade de fontes, Duby afirma que “[...] nós utilizamos esse material, criticamente analisado, com a maior liberdade, tendo plena consciência de que jamais chegaremos a uma verdade objetiva" (DUBY, 1986, p. 11)

Há uma variedade de núcleos temáticos, objetos, atores e com a valorização de uma história "problemática" e não meramente "automática", como ocorria com a história tradicional.

Jacques Le Goff, por exemplo, vai afirmar que neste contexto de novos núcleos temáticos

\footnotetext{
"A história do quotidiano é uma visão autêntica da história porque representa uma das melhores formas de abordagem da história global, na medida em que atribui a cada actor e a cada elemento da realidade histórica um papel, no funcionamento dos sistemas, que permitem decifrar essa realidade" (LE GOFF, 1986, p.82)
} 
Para Ladurie (1987), os historiadores têm se interessado mais pelas massas que pelas elites, mais pela encarnação social das idéias do que pela produção intelectual dos grandes pensadores. Dessa forma, os principais temas abordados pelos autores contemporâneos, no trato da história, são: exame da história das idéias no seu quadro material e econômico, análise das principais obras no seu meio cultural ou no seu enquadramento sócio-cultural; estudo do enraizamento dos sistemas de pensamento religioso na sensibilidade popular, nas crenças gerais.

Assim, a construção do tempo prioriza uma história da dinâmica social e não uma história estática; a história dos homens e não só dos líderes, a história das estruturas e não só dos acontecimentos; a história explicativa e não só a narrativa ou dogmática. Para Duby, “[...] o discurso histórico continua a ser uma forma de criação, no qual a sensibilidade e a arte de escrever desempenham, em meu entender, um papel necessário.” (DUBY,1986, p. 8)

Como sói acontecer com inúmeros historiadores da nova história, Ladurie defende a ideia de mudança de perspectiva e de orientação metodológica afirmando, por exemplo, que a tônica dada aos seus trabalhos é a de uma história relativamente material ou social. Assim,

[...] quer sob a influência de uma evolução geral da cultura francesa actual, que se afastou do marxismo desde há uns vinte anos, quer devido ao aprofundamento problemático [...], pareceu-me que o aspecto espiritual e o aspecto intelectual, em suma, o aspecto mental - que impregna tudo, pois a economia baseia-se também nas mentalidades -, merecia ser considerado para melhor compreender quem faz a história. (grifos acrescidos, LADURIE, 1987, p.113)

No que concerne ao tempo nesta nova história, busca-se uma história de longa duração, cujas estruturas mudam lentamente através da aceitação da diversidade de "mentalidades" e de pensamentos.

Neste sentido, Aries afirma que

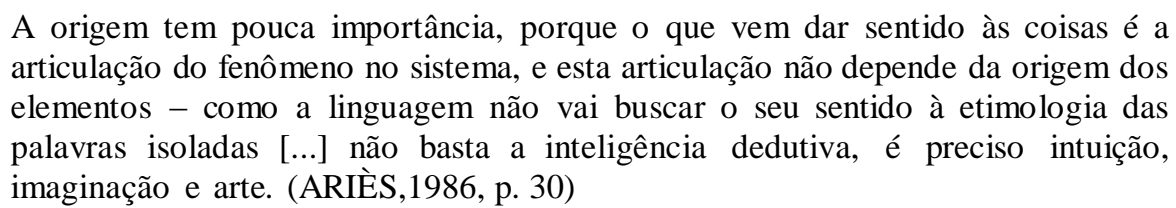

Apesar de alterar definitivamente o quadro da historiografia, alguns problemas surgem na metodologia da nova história: a construção do tempo, do espaço, a multiplicidade de agentes e de fontes e uma tendência ao determinismo. A própria ideia de história total é questionada pela maioria dos historiadores contemporâneos. Além disto, observa Ariès, que 
“[...] este fascínio pela mudança e pela diferença parece-me, actualmente, estar a desaparecer entre as gerações de historiadores mais jovens.” (ARIÈS, 1986, p. 27)

\title{
3. A METODOLOGIA DA HISTÓRIA DE ISABEL PÉREZ MOLINA
}

No estudo Las mujeres ante la ley en la Cataluña moderna (2008) a autora entende que a História é um conhecimento que, como todo estudo científico, pode sofrer modificações à luz de novos dados. Pérez Molina afirma que

\begin{abstract}
A história não é neutra, mas sim embasa-se numa seleção de dados do passado. O resultado depende da escala de valores que tomamos ao escolher a informação e dos questionamentos que fazemos às fontes. Depende, portanto, de quem faz e de quem apoia a tarefa do historiador. (PÉREZ MOLINA, 2008, p. 21)
\end{abstract}

Os critérios metodológicos traçados pela autora nesse texto, circunscrevem-se a três aspectos principais: marco espacial e temporal, metodologia e fontes.

O marco temporal utilizado por Molina é o do "Antigo Regime", que compreende o período do Século XVII ao Século XIX, com ênfase dada ao Século XVIII. A escolha desse marco temporal deveu-se às seguintes razões: a) é um período de transição onde ocorreram diversos acontecimentos sócio-políticos na Europa e b) é o momento em que surgem as figuras mais relevantes do Direito Civil Catalão. Segundo Molina, “A eleição do Século XVIII para a documentação notarial e processual obedece ao fato de que este século constituiu um período de mudança importante marcado na Catalunha em nível legislativo" (PÉREZ MOLINA, 2008, p. 14).

O marco espacial de estudo, bem delimitado pela autora, é o território da Catalunha, por se tratar de uma região peculiar e própria. A documentação notarial analisada circunscreveu-se, notadamente, na cidade de Barcelona. A razão da escolha dessa área de estudo foi o fato de que "[...] o Principado da Catalunha conservou durante a época moderna suas instituições próprias e seu direito particular, os quais, por outro lado, contavam já com uma larga tradição até chegar a este período.” (PÉREZ MOLINA, 2008, p.13) 
Sua escrita histórica possui conotação urbana, tendo em vista a seguinte afirmação: "O interesse que desperta uma importante zona urbana como Barcelona marca esta eleição espacial” (PÉREZ MOLINA, 2008, p. 14)

As fontes consultadas por Molina foram 668 documentos (capítulos matrimoniais e testamentos) expedidos por diferentes notários no período de 1770 a 1800. Foram utilizadas fontes de outros anos (1701 a 1707 e 1759 a 1770) para comprovar se havia algum tipo de variação dos institutos e práticas sociais; a legislação livre vigente no período estudado e obras de juristas catalãos dos Séculos XVII e XIX. Neste último século o levantamento foi feito para comprovar a persistência no tempo de algumas concepções e atitudes. Além disso, os documentos pesquisados referem-se a práticas tipicamente urbanas: assentamentos notariais de casamento, testamentos, codicilos e outros documentos, como doações, dotes e patrimônio.

A realização deste trabalho, segundo Molina, teve por objetivo "[ [...] ajudar a entender o funcionamento da justiça moderna levando em conta a existência de uma hierarquia de gêneros." (PÉREZ MOLINA, 2008, p. 13)

Para alcançar essa finalidade, a metodologia utilizada procurou:

- Reconstruir o sistema de valores no qual se moviam as mulheres durante o Antigo

- Verificar a materialização do discurso jurídico nos documentos notariais

- Intuir se esse discurso jurídico se refletia realmente na pratica cotidiana e sobretudo na pratica notarial

Ainda no intuito de compor a metodologia utilizada no texto, Isabel Pérez Molina faz rápida evolução histórica dos três principais modelos de história das mulheres: o feminismo materialista, a teoria dos gêneros e o pensamento da diferença sexual.

A história das mulheres, segundo a autora, nasceu impulsionada pelo movimento feminista, pois as mulheres somente se converteram em sujeito histórico na medida em que se inseriram no processo político. 
$\mathrm{O}$ feminismo materialista considera as mulheres como classe social e a base última da opressão feminina encontra-se na vida material, na exploração específica que padecem as mulheres.

A teoria do gênero reivindica a utilização do gênero como categoria histórica imprescindível para realizar qualquer tipo de investigação. É uma teoria marcada pela interdisciplinariedade, especialmente quando se refere à diferenciação entre papéis sexuais físicos e papéis sexuais sociais, ou seja, o sexo biológico e o sexo social.

O pensamento da diferença sexual, por sua vez, reconheceu a definição de uma identidade feminina independente dos processos que intervêm na formação da identidade masculina.

O pensamento da diferença sexual parte da necessidade de sexualizar a análise haja vista que as relações sociais e o discurso que delas deriva não é neutro, mas sim um discurso sexuado em masculino, que identifica sexualidade masculina com sexualidade humana.

Conclui Pérez Molina que, a despeito dessa construção histórica, surge o patriarcado, um sistema de dominação e subordinação das mulheres, que tem perdurado através das culturas e das épocas históricas. Para a autora,

Ele implica que os homens têm o poder em todas as instituições importantes da sociedade em geral e que as mulheres são privadas de acessá-lo. Não implica que as mulheres não tenham nenhum tipo de poder ou que se as tenha privado por completo de direitos, influência e recursos. (PÉREZ MOLINA, 2008, p. 30)

Observa-se, ainda, na obra estudada, uma influência da história social sobre as mulheres perante a lei na Catalunha Moderna, pois a autora considera a história social como o momento do surgimento da história das culturas populares, bem demarcada na obra de Natalie Davis (1997).

Considerando o objetivo deste trabalho descrito anteriormente - comparar a metodologia da "Nova História" àquela utilizada por Isabel Pérez Molina, passa-se a análise das metodologias. 


\section{CONTRAPONDO A "NOVA HISTÓRIA" E A METODOLOGIA DA HISTÓRIA EM "MULHERES PERANTE A LEI NA CATALUNHA MODERNA"}

De início, podemos afirmar que existem elementos que aproximam Pérez Molina da metodologia da "Nova história", em que pese a autora não ter feito a indicação precisa desta escola do pensamento na metodologia do seu trabalho. Entre esses elementos podemos destacar os seguintes:

a) Tempo da escrita da história: momento contemporâneo

Por se tratar de autora contemporânea, Pérez Molina sofre influência de inúmeros movimentos da "Nova História". A autora mantém uma postura crítica diante da história tradicional, razão pela qual procura enfatizar as mudanças ocorridas nas últimas décadas no campo da história e justificar a escolha e a importância do tema que desenvolve. Neste sentido, afirmou que "Nos últimos vinte anos, os avanços na investigação história e na política feminista têm feito questionar o que antes se concebia como história [...]" (PÉREZ MOLINA, 2008, p.21).

b) Crítica à História Social

Pérez Molina reconhece o papel desempenhado pela História Social para o surgimento da história das mulheres, ao afirmar que:

[...] os estudos de Natalie Z. Davis sobre a cultura popular, o trabalho e o papel das mulheres na sociedade do século XVI constituíram um avanço importante na investigação sobre as mulheres na Idade Moderna. Essas influências constituíram um ponto de referência para os estudos sobre a marginalidade, a família ou as associações. (PÉREZ MOLINA, 2008, p. 32)

Segundo a autora, entretanto, novos estudos e a alteração de perspectiva da história fizeram com que essa tendência se superasse na metodologia da história, em que pese sua importância.

c) Imparcialidade do historiador 
Pérez Molina (2008) - assim como outros historiadores contemporâneos - rompe com a neutralidade e a imparcialidade do historiador. Nas ciências sociais não mais persiste a ideia de distinção entre sujeito e objeto do conhecimento: o objeto é construído pelo sujeito ao mesmo tempo que esse é influenciado pelo objeto que quer conhecer, havendo uma interdependência entre eles.

d) Análise de discurso

No trabalho de Pérez Molina percebeu-se a preocupação em trabalhar uma reconstrução do sistema de valores no qual se moviam as mulheres da Idade Moderna e de que maneira se realizava a materialização do discurso jurídico na prática notarial desse período.

Trata-se de expediente utilizado por outros expoentes da Nova História, como Emmanuel Le Roy Ladurie. Em entrevista dada sobre a escrita de sua obra, o próprio autor concluiu que alterou a perspectiva de análise de suas obras, atribuindo maior valor à simbologia do discurso do que à descrição das coisas. Em Montaillou, por exemplo, Ladurie utilizou-se dos processos e interrogatórios inquisitoriais feitos por Jacques Fournier (futuro bispo de Avignon) para construir a história de uma massa esmagadora de gente miúda, camponeses, artesãos, comerciantes ínfimos, da aldeia de Montaillou, no sul da França. $\mathrm{Na}$ análise dessas fontes, afirmou o autor:

As confissões estão escoradas, assentadas, nas descrições fornecidas pelos acusados sobre suas 'fatias de vida', cotidianas e substanciais. O que anima nosso prelado é o ideal de uma investigação (odiosa, no caso) sobre a verdade dos fatos. (LADURIE, 2008:17; grifos acrescidos)

e) História problemática

Como visto, a história problemática, e não meramente automática, é uma característica peculiar da Nova História e, em Pérez Molina, a problematização é um aspecto central de sua obra, seja pela escolha do tema, formas de abordagem, construção da metodologia da história a partir do gênero, entre outras questões anteriormente analisadas.

f) Multiplicidade de métodos: história quantitativa e qualitativa 
O Positivismo, como visto foi, durante longo tempo, influência importantes do conhecimento histórico e dos métodos empregados pela História. Assemelhava-se muito aos métodos experimentais e quantitativos. A autora estudada não descartou o uso de fontes documentais e descrições quantitativas, mas as mesmas são instrumentais na medida em que ajudam a compreender, qualitativamente, o objeto de trabalho. Verifica-se, então, duas abordagens que se complementam: a qualitativa e a quantitativa, esta última com o auxílio de medidas e experimentações.

\section{g) Tempo e espaço}

A autora preocupa-se com a delimitação espaço-temporal. Talvez essa seja uma obsessão necessária dos historiadores, no sentido de embasar a produção do conhecimento histórico. Como ocorre no pensamento da Nova História, a delimitação do tempo e do espaço não é rígida, na medida em que sua plasticidade ajuda a compreender o objeto que se quer compreender. Nesse sentido, Pérez Molina, quando delimita o tempo em que empreenderá suas análises históricas admite que algumas observações extemporâneas sejam feitas para compreender a influência e permanência de alguns institutos em época diversa, o mesmo ocorrendo com o local, dependendo, obviamente, do tema que está sendo trabalhado. É da autora a observação de que "Qualquer periodização é arbitrária e excludente [...] a história foi periodizada sem levar em conta as experiências das mulheres, que tinham sido sistematicamente consideradas como irrelevantes." (PÉREZ MOLINA, 2008, p. 32)

h) Fontes de pesquisa

A principal fonte utilizada é a documental, com ênfase na análise de conteúdo dessas fontes. É sem dúvida muito difícil para Pérez Molina, sem recorrer a outras fontes de pesquisa, construir uma história das mulheres de determinada época através de assentamentos notariais de casamento, de testamentos e codicilos, razão pela qual passou a observar a legislação da época e as obras doutrinárias de diversos autores. As fontes utilizadas por Pérez Molina são mais restritas que as propostas pela "Nova História", que apela pela sua multiplicidade. Um outro aspecto importante a ser abordado com relação às fontes utilizadas, diz respeito ao senso crítico com que as tratam. Neste sentido, Pérez 
Molina, em que pese se preocupar em apresentar as fontes utilizadas, não lhes dirige qualquer observação.

i) Metodologia e marco teórico

Pérez Molina, depois de citar as várias tendências do pensamento histórico, e, sobretudo, do pensamento feminista, não apresenta uma opção metodológica ou direções teóricas a serem seguidas em seu trabalho. Alguns autores que discutem epistemologia da ciência, acreditam que o marco teórico escolhido pelo autor é um dos componentes da metodologia a ser utilizada no trabalho. Nesse sentido, Pérez Molina não apresenta nenhuma dessas opções: não apresenta a metodologia a ser utilizada e nem mesmo o marco teórico adotado.

j) História estrutural e História do acontecimento

Não se pretende solucionar a controvérsia sempre discutida nos estudos históricos sobre a importância dada ao acontecimento em detrimento de uma história tão somente estrutural. Alguns metodólogos, inclusive, entendem que o acontecimento compõe, inexoravelmente, a estrutura, impondo-lhe dinamismo e mudança. A autora analisada tende a fazer essa dupla análise, ora dando ênfase ao acontecimento, ora à análise das estruturas sociais. Na obra de Pérez Molina, portanto, a perspectiva estrutural é evidente.

\section{CONCLUSÕES}

Quanto a influência da "Nova História" no trabalho de Pérez Molina, sobre as "Mulheres perante a lei na Catalunha moderna" a partir da análise dos seus elementos metodológicos, demonstrou-se que a autora - em que pese não afirmar textualmente produziu um trabalho atendo às principais questões metodológicas desta corrente de pensamento, notadamente quanto aos seguintes aspectos: a investigação histórica na política feminista; a ruptura com a neutralidade e a imparcialidade do historiador a partir da reconstrução do sistema de valores no qual se moviam as mulheres da Idade Moderna; 
história problemática e não apenas automática; multiplicidade de métodos - história quantitativa e qualitativa.

Como críticas ao livro estudado - que não chegam a contrastar com a "Nova história" mas podem apontar para aperfeiçoamentos na metodologia desenvolvida, destacou-se a ausência de um referencial teórico mais bem definido e a maior pluralidade das fontes, vez que o trabalho centrou-se na análise documental.

Para aqueles que sempre viram a História como conjunto de fatos do passado bem documentados - e por vezes empoeirados e mofados - o estudo das metodologias da história mostra o dinamismo, originalidade, imaginação e criatividade que podem ser dadas ao estudo e à escrita da história do direito.

Além disto, considerando os aspectos e temáticas que esta "Nova História" pode abordar, ela tem mais condição hoje do que no passado, de contribuir para a construção e compreensão dos fenômenos sociojurídicos do passado, notadamente na temática das mulheres.

Quanto a possibilidade de existir uma história total, de homens e mulheres, Pérez Molina acredita que somente se pode construir uma verdadeira história total com a inserção das mulheres no processo histórico. Entretanto, faz uma análise fracionada da realidade, observando tão somente a história das mulheres. Seu objetivo talvez seja construir a "outra metade" que falta à história. Assim, não se pode jamais afirmar que essa autora trabalha uma história total, mas sim, uma história parcial, somente das mulheres.

Trata-se de exercício importante para visibilizar atores e situações que até então não faziam parte da "história universal". 


\section{REFERÊNCIAS}

BURKE, Peter. A Escola dos Annales. São Paulo: UNESP, 1990.

DAVIS, Natalie Zemon. Women on the margins: three seventeenth-century lives. Cambridge, MA: Harvard University Press, 1995.

DEMO, Pedro. Metodologia científica em ciências sociais. São Paulo: Atlas, 1995.

DUBY, Georges, ARIÈS, Philipe, LADURIE, Emmanuel, LE GOFF, Jacques. História e Nova história. Lisboa: Teorema, 1986.

GUSTIN, Miracy Barbosa de Sousa et al. Introdução: a história de uma obra coletiva e de uma metodologia. In: GUSTIN, Miracy Barbosa de Sousa; SILVEIRA, Jacqueline Passos da; AMARAL, Carolline Scofield (org.) História do direito: novos caminhos, novas versões. Belo Horizonte: Mandamentos, 2007.

HESPANHA, António M. A história do direito na história social. Lisboa: Livros Horizonte, 1978.

HUNT, Lynn. A nova história cultural. São Paulo: Martins Fontes, 1992.

LADURIE, Emmanuel Le Roy. Entrevistas. Revista Ler História. Lisboa, v. 11, Salamandra e Calouste Gulbenkian, p. 108-116, 1987.

LE GOFF, Jacques, DUBY, Georges, ARIÈS, Philipe, LADURIE, Emmanuel Le Roy. História e Nova história. Lisboa: Teorema, 1986.

LE GOFF, Jacques. Reflexões sobre a história. Lisboa: Edições 70, 2009.

MATA, Sérgio da. Ranke reloaded: entre história da historiografia e história multiversa.

História da historiografia, Ouro Preto, n. 6, mar, 2011, p. 247-251. MIAILLE, Michel. Introdução Crítica ao Direito. Lisboa: Estampa, 1989.

PÉREZ MOLINA, Isabel. Las mujeres ante la ley en la Cataluña moderna. Granada: 2008.

POPPER, Karl. A lógica da pesquisa científica. São Paulo: Cultrix, 1993.

REIS, José Carlos. Nouvelle histoire e tempo histórico. São Paulo: Ática, 1994. SCHAFF, Adam. História e verdade. São Paulo: Martins Fontes, 1980.

WOLKMER, Antônio Carlos. História do direito no Brasil. 5 ed. Rio de Janeiro: Forense, 2010. 